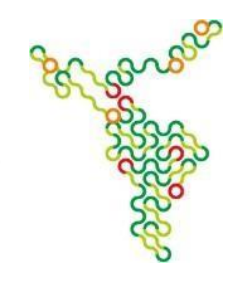

\title{
"QUANDO MENOS PERCEBEMOS ESTAMOS ALI CONECTADOS": ESTUDO SOBRE AS PRÁTICAS COTIDIANAS DO USO DO SMARTPHONE DE JOVENS UNIVERSITÁRIOS
}

Luciane Pereira Viana ${ }^{1}$

Resumo: Este estudo tem como objetivo analisar as perspectivas de jovens universitários da cidade de Novo Hamburgo-RS, a respeito da utilização do smartphone para agilizar práticas cotidianas. A afirmação que as tecnologias estão cada vez mais interligadas ao processo de inclusão social, revela- se o fio condutor para a reflexão sobre os processos de subjetivação e conectividade que atravessam o cenário atual das práticas culturais juvenis. Neste artigo utilizou-se a pesquisa descritiva, qualitativa, com abordagem etnográfica e entrevistas realizadas com jovens universitários na cidade de Novo Hamburgo-RS em 2017. O referencial teórico, conta com os autores Feixa Pampols, Santos, Pais, Castells, Canclini, Reguillo Cruz, entre outros. Os resultados apontam que não importa onde, quando e os motivos do consumo, o fato é que os aparatos tecnológicos estão cada vez mais imersos no cotidiano dos jovens. Assim, conhecer o processo de inclusão digital das juventudes é essencial a fim de que se possam propor sugestões para promoção social (educação, trabalho, cultura, etc.), maior liberdade e igualdade de oportunidades. Este artigo traz reflexões que integram a pesquisa em andamento de doutoramento em Diversidade Cultural e Inclusão Social pela Universidade Feevale que tem objetivo central problematizar a relação do consumo com a inclusão social na juventude contemporânea brasileira.

Palavras-chave: Juventudes. Smartphone. Inclusão Digital. Consumo.

\section{“WHEN UNLESS WE UNDERSTAND WE ARE ALI CONNECTED”: STUDY ON THE DAILY PRACTICES OF SMARTPHONE USE OF YOUNG UNIVERSITY STUDENTS"}

\begin{abstract}
This study aims to analyze the perspectives of young university students in the city of Novo Hamburgo-RS, regarding the use of smartphones to streamline daily practices. The assertion that technologies are increasingly linked to the process of social inclusion reveals the guiding thread for reflection on the processes of subjectivation and connectivity that cross the current scenario of youth cultural practices. In this article we used the descriptive and qualitative research, with an ethnographic approach and interviews with university students in the city of Novo Hamburgo-RS in 2017. The theoretical framework has the authors Feixa Pampols, Santos, Pais, Castells, Canclini, Reguillo Cruz, among others. The

\footnotetext{
${ }^{1}$ Doutoranda em Diversidade Cultural e Inclusão Social na Universidade FEEVALE, Bolsista PROSUC/CAPES. Mestra em Processos e Manifestações Culturais. Administradora. Docente na Faculdade IENH - Novo Hamburgo/RS. Saraí Patrícia Schmidt - Professora orientadora. Doutora em Educação e mestra na linha de pesquisa Estudos Culturais da UFRGS. Jornalista. Docente na Universidade FEEVALE - Novo Hamburgo/RS.
} 


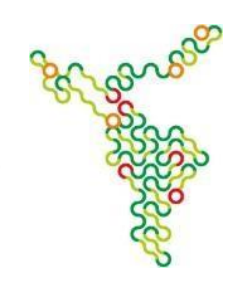

results point out that no matter where, when and the reasons for consumption, the fact is that technological devices are increasingly immersed in the daily lives of young people.Thus, knowing the process of digital inclusion of youth is essential so that suggestions can be made for social promotion (education, work, culture, etc.), greater freedom and equal opportunities. This article brings reflections that integrate the research in progress of PhD in Cultural Diversity and Social Inclusion by the University Feevale that has central objective to problematize the relation of the consumption with the social inclusion in the Brazilian contemporaneous youth. Keywords: Youth. Smartphone. Digital Inclusion. Consumption.

\section{Introdução}

A afirmação que as tecnologias estão cada vez mais interligadas ao processo de inclusão social, revela-se o fio condutor para a reflexão sobre os processos de subjetivação e conectividade que atravessam o cenário atual das práticas culturais juvenis.

No mundo a quantidade de celulares (soma da quantidade de celulares e smartphones) atingiu 97,8 acessos por cem habitantes em 2015, com um total de 7,2 bilhões de aparelhos (Gráfico 1) que representa praticamente um acesso para cada indivíduo. Sendo que o consumo de telefones celulares teve um crescimento de $227 \%$ nos últimos dez anos (2005 a 2015). Segundo a GSMA (2018) estimase que em 2025 tenhamos 9,0 bilhões de aparelhos com cartão SIM, com 110\% de penetração mundial.

Gráfico 1 - Quantidade de celulares no mundo: 2000 a 2015 (em bilhões de aparelhos)

\section{Celulares no Mundo}

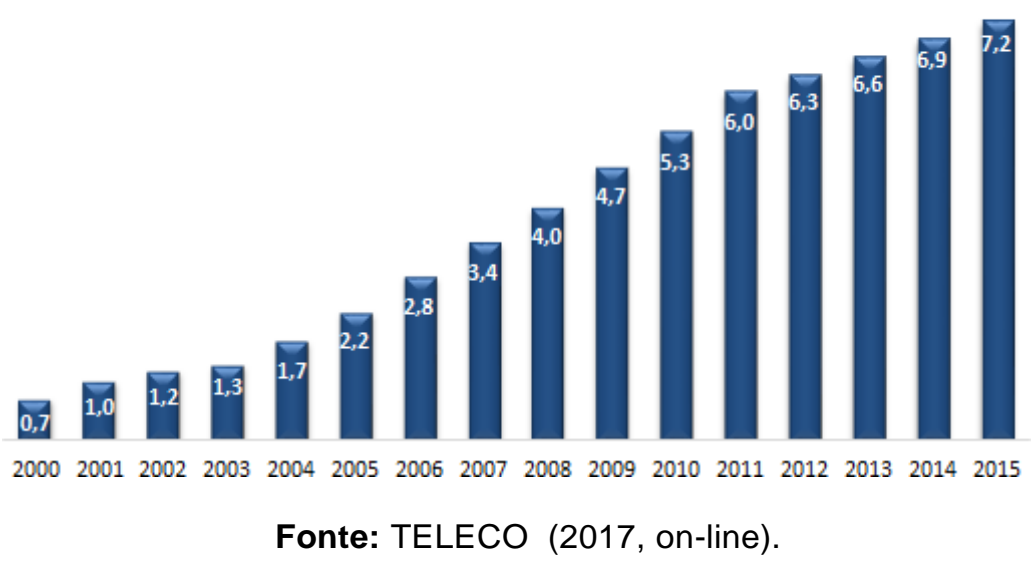

Revista Ibero-Americana de Humanidades, Ciências e Educação. Criciúma, v. 6.n.5 2020. 


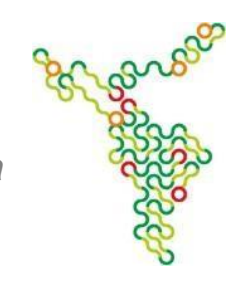

Contudo, além do aumento expressivo da quantidade de celulares nos últimos anos apresentado no Gráfico 1, destacamos que a medida que os dispositivos se tornam mais inteligentes, as sociedades estão mais conectadas e os serviços ficam mais ricos, principalmente no que diz respeito ao avanço de funcionalidades. A telefonia móvel, utilizada na função "fazer e receber ligação", adquire o "status" de telecomunicação móvel, abrangendo várias formas de interação, informação e comunicação.

Ou seja, os smartphones podem ser considerados "computadores de bolso", com os quais podemos obter informações, fazer compras, acessar redes sociais, assistir filmes e ouvir músicas, enfim, diversas atividades na hora em que surge a necessidade ou desejo. Cabe destacar que o smartphone tornou-se uma prática de sociabilidade de grande valor simbólico na juventude. Assim, este estudo tem como objetivo analisar as perspectivas de jovens universitários da cidade de Novo Hamburgo-RS, a respeito da utilização do smartphone para agilizar práticas cotidianas.

No percurso metodológico utilizou -se a pesquisa descritiva, qualitativa, dividida em dois procedimentos: bibliográfica e etnográfica (PRODANOV E FREITAS, 2009). A pesquisa bibliográfica busca discutir questões sobre 0 consumo do smartphone e as culturas juvenis e, conta com os autores Feixa Pampols, Santos, Pais, Castells, Canclini, Reguillo Cruz, entre outros.

A parte da pesquisa etnográfica descrita neste artigo, contou o relato de cinco entrevistas realizadas com jovens universitários na cidade de Novo Hamburgo-RS, no ano de 2017. Por fim, optou-se pela análise de conteúdo, segundo Bardin (2004), sendo obedecidas as seguintes fases: a) pré-análise com preparação do material com a escolha dos relatos para compor o artigo; b) exploração do material, com definição das categorias; c) tratamento dos resultados, inferência e interpretação.

Este artigo traz reflexões que integram a pesquisa em andamento de doutoramento em Diversidade Cultural e Inclusão Social pela Universidade Feevale que tem objetivo central problematizar a relação do consumo com a 
inclusão social na juventude contemporânea brasileira.

\title{
Culturas Juvenis, Inclusão Digital e Práticas Cotidianas
}

Entender a juventude implica em não homogeneizá-la, afinal suas linguagens, performances e representações de seus corpos constroem e (re)configuram suas identidades e os espaços sociais de que participam. Pode-se considerar que a ambiguidade (comportamento homogêneo e heterogêneo) da vida social juvenil é um reflexo da influência da cultura híbrida com que eles convivem. Neste sentido, um aspecto é importante: a questão da juventude acompanhar a liquidez da sociedade.

Schmidt (2007, p. 12), tendo como base Bauman (2001), caracteriza a "juventude líquida" como:

\begin{abstract}
um grupo que, para afirmar-se como tal, precisou, em determinados momentos históricos, romper, ou talvez fosse melhor dizer, dissolver, derreter certos "sólidos". Nesse processo de dissolução, a juventude acabou por constituir-se como "rebelde", "irreverente", "obstinada", "inconformada". Com isso, acabou criando novos "sólidos" para si. E são eles que, contemporaneamente, vão sendo despejados no cadinho para serem novamente reformados, reformulados e refeitos.
\end{abstract}

Um dos efeitos marcantes desse processo é o modo dinâmico, fluido, fugaz, múltiplo do estilo de vida jovem. Feixa Pampóls (1999) destaca que a construção de distintos estilos de vida refere-se ao modo como as experiências dos jovens são coletivamente expressas e formam um conjunto de formas de vida e valores característicos e distintos de determinados grupos juvenis que, em sentido amplo, constituem a expressão "culturas juvenis". Importante destacar que o autor indica culturas juvenis no plural, tendo como base a diversidade e complexidade da construção desta categoria social. Pais (2003, p. 54, grifo do autor) explica que "por cultura juvenil, em sentido lato, pode entender-se o sistema de valores socialmente atribuídos à juventude (tomada como um conjunto referido a uma fase de vida), isto é, valores a que aderirão jovens de diferentes meios e condições sociais". A partir deste conceito, remetem-se também as demais características citadas por Reguillo Cruz (2003, p. 103, tradução nossa) que 


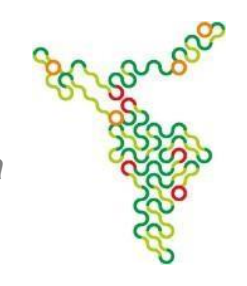

afirma que as culturas juvenis são "caracterizadas por seus sentidos múltiplos e móveis, incorporam, descartam, misturam, inventam símbolos e emblemas, em contínuo movimento quetorna difícil representá-los em sua ambiguidade". Contudo, os jovens são vítimas das desigualdades do atual contexto socioeconômico da sociedade, conforme Reguillo Cruz (2012) as juventudes vivem

a instabilidade e a incerteza de acesso à educação formal, os problemas de inserção no mundo do trabalho, entre outras múltiplas formas de exclusão em termos de cidadania cívica, política, cultural e social.

Para Santos (2008, p. 280) a exclusão é a precarização da população em contextos de enormes divisões, discriminações, privações e desigualdade social. Segundo Castells (2003) o processo de exclusão digital possui relação direta com o processo de exclusão social, uma vez que, o processo de inclusão digital prevê ampliação da cidadania e do direito de comunicação na esfera on-line.

Sendo que, a inclusão digital insere-se em uma discussão mais ampla com profissionalização, capacitação e inserção no mercado de trabalho e, também no âmbito da educação, ou seja, o sujeito deve ter inteligência e capacidade técnica de atuar na rede, criar e produzir conteúdos e significados (Silveira, 2002). Castells (2003) defende que atualmente a internet constitui -se o epicentro de atividades sociais, econômicase políticas.

Segundo Mari, uma das entrevistadas: "Tendo wi-fi ou um plano de internet, não é preciso um computador, nem jornais, para ficar por dentro do que acontece ao redor do mundo. Além disso, não é preciso sair de casa para pagar contas, consultar faturas e extratos. Podemosinclusive, decidir o que preparar na refeição, através de aplicativos com receitas diversas". E, conforme a entrevistada Anna "Hoje se consegue fazer praticamente tudo pela internet, então também há possibilidade de fazer por um smartphone".

Canclini (2010, p. 40) explica que o novo cenário sociocultural, expõe uma reformulação dos padrões "[...] onde as atividades básicas (trabalhar, estudar, consumir) se realizam frequentemente longe do lugarde residência e onde o tempo empregado para locomover-se por lugares desconhecidos da cidade reduz 0 tempo disponível para habitar a própria". O que concorda a entrevistada Mel "O 
smartphone agiliza o pagamento de contas, indica uma direção/caminho para chegar em um lugar que não conhecemos e também faz com que fugimos do trânsito intenso indicando o melhor caminho".

A temporalidade efêmera faz com que a urgência predomine no cotidiano da sociedade de consumo; o importante é o maior tempo livre para se dedicar a outros consumos. Ou seja, na sociedade atual, ganhar/perder tempo com entretenimento, convívio, cuidado de si está vinculado não somente a capacidade financeira, mas também, ao tempo disponível. A respeito disto, Bauman (2008, p. 45) descreve que:

\footnotetext{
Stephen Bertman cunhou os termos 'cultura agorista' e 'cultura apressada' para denotar a maneira como vivemos em nosso tipo de sociedade. Termos de fato adequados, que se tornam particularmente úteis sempre que tentamos apreender a natureza do fenômeno líquidomoderno do consumismo.
}

Nsta perspectiva, se faz necessário refletir que "através da tecnologia, diversão obrigação, entretenimento e trabalho, se intercalam, reorganizando, de maneira não-linear, o tempo livre e o tempo útil, que se misturam em diferentes espaços sociais, privados e públicos" propõem Rocha, Pereira e Balthazar (2010, p. 2).

Relata a entrevistada Bela "O smartphone deixou de ser um acessório e passou ser uma necessidade, ele é muito prático, é difícil vermos hoje em dia pessoas com notebooks em mãos, porque não tem necessidade de carregar ele toda hora, o smartphone veio para ser prático, tudo o que tu faz em um computador hoje, tu consegue fazer pelo próprio celular, eu mesma, várias vezes cheguei na escola estudando para provas ou apresentações pelo próprio celular".

O smartphone tem presença garantida em casa, no trabalho, na escola e no lazer, algumas vezes podendo até diluir as fronteiras entre pessoal e profissional, no sentido de tempo e espaço (Castells, 2003). Sendo assim,

ocupar o tempo ganha um significado importante; mais ainda, fundamental para os jovens que, comumente, são caracterizados pela falta de tempo, pelo grande número de compromissos, pela enorme capacidade de fazer inúmeras tarefas simultaneamente. O tempo, quando ocupado intensamente, torna-se produtivo e distintivo ( $\mathrm{ROCHA}$, PEREIRA, BALTHAZAR, 2010, p. 8). 


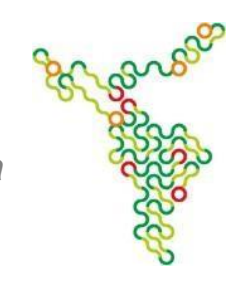

Diante disso, não é exagero pensar que o smartphone e as demais tecnologias permitem construir um ambiente de cultura de consumo integrado, que permite cada vez mais que os jovens "vivam conectados". Conforme Rosa (2011, p. 1), "esses pequenos aparelhos eletro-eletrônicos parecem parte essencial do corpo de muitos indivíduos, não é raro vermos em todos os lugares, tanto nos centros urbanos quanto no meio rural, homens e mulheres fazem uso dessas novas tecnologias".

O que remete ao comentário da entrevistada Elsa " $O$ smartphone faz parte de todo nosso dia a dia. Quando menos percebemos estamos ali conectados, tirando fotos, buscando resultados na Internet e fazendo pesquisas. Algo que simplifique nossa rotina, está ali para todos os momentos, com inúmeras formas de notificações que podem ser implantadas hoje em dia para melhorar e facilitar nossa vida".

Estamos cercados de dispositivos tecnológicos e, principalmente, smartphones que interpelam as funções e formas que os jovens veem, leem, ouvem e se conectam. É possível observar uma mudança de práticas de consumo que a tecnologia digital introduziu na vida cotidiana dos jovens. $E$, que o smartphone não é simplesmente um dispositivo individualizado, mas um instrumento de articulação de novas formas de comunicação, informação e conectividade das juventudes contemporâneas.

\section{Considerações parciais}

Este artigo apresentou alguns apontamentos sobre culturas juvenis e o consumo do smartphone, com foco em refletir sobre o processo de inclusão digital que envolve as experiências de consumo do smartphone na juventude contemporânea brasileira, a partir de entrevistas com jovens estudantes universitários sobre a utilização do smartphone para agilizar práticas cotidianas.

Os resultados apontam que não importa onde, quando e os motivos do consumo, o fato é que os aparatos tecnológicos estão cada vez mais imersos no cotidiano dos jovens. O smartphone é capaz de atender de modo personalizado as necessidades dos jovens e agilizar as rotinas diárias, bem como permite 


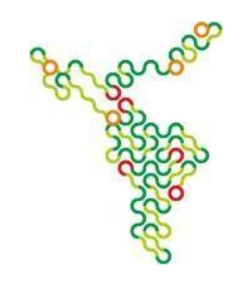

interação e compartilhamento de informações, entre tantas funções.

Pode-se constatar que, para a inclusão digital não é suficiente apenas possuir um smartphone, pois os diversos usos e possibilidades podem acarretar que o jovem mesmo possuindo um smartphone possa sentir-se excluído da lógica da modernidade mundial. Para tanto, acredita-se que o acesso à informação e comunicação mostra-se fundamental para a inclusão dos jovens na sociedade contemporânea. Enfim, os jovens precisam entender a importância da apropriação e utilização deste dispositivo, de forma a traduzir em práticas de maior autonomia e cidadania.

Assim, acredita-se que o problema proposto inicialmente tenha sido respondido e o objetivo alcançado, em função da apresentação da base teórica correspondente ao tema e da identificação desta bibliografia aos comentários analisados. Por fim, observa-se que conhecer o processo de inclusão digital das juventudes é essencial a fim de que se possam propor sugestões para promoção social (educação, trabalho, cultura, etc.), maior liberdade e igualdade de oportunidades.

\section{Referências}

BARDIN, L. Análise de Conteúdo. Lisboa: Edições 70, 2004. BAUMAN, Z.

Modernidade Líquida. Rio de Janeiro: Zahar, 2001.

. Vida líquida. Rio de Janeiro: Zahar, 2007.

. Vida para consumo: a transformação das pessoas em mercadorias. Rio de Janeiro: Zahar, 2008.

CANCLINI, N. G. Culturas Híbridas: Estratégias para Entrar e Sair da Modernidade. São Paulo: Editora da Universidade de São Paulo, 2003.

. Consumidores e cidadãos: conflitos multiculturais da globalização.

8. ed. Rio de Janeiro: UFRJ, 2010.

CASTELLS, M. Internet e sociedade em rede. In: MORAES, D. Por uma outra comunicação. Rio de Janeiro: Record, 2003.

FEIXA PAMPÓLS, C. De jóvenes, bandas y tribus. Barcelona: Ariel, 1999. 


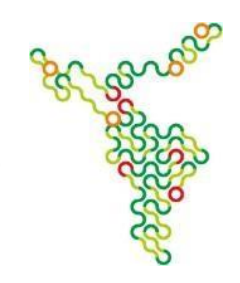

. Generación @ la juventud en la era digital. Nómadas, Bogotá, Colombia, p. 76-91, Out. 2000.

GSMA. The Mobile Economy 2018. GSMA HEAD OFFICE, 2018. Disponível em: <www.gsma.com>. Acesso em: 26 Fev. 2019.

PAIS, J. M. Culturas Juvenis. Lisboa: Imprensa Nacional da Casa da Moeda, 2003.

PRODANOV, C. C.; FREITAS, E. C. Metodologia do Trabalho Científico:

Métodos e Técnicas

da Pesquisa e do Trabalho Acadêmico. 2. ed. Novo Hamburgo: Feevale, 2013.

REGUILLO CRUZ, R. Las culturas juveniles: un campo de estudio; breve agenda para la discusión. Revista Brasileira de Educação, p. 103-118, Maio-Ago. 2003. Disponível em: http://www.redalyc.org/articulo.oa?id=27502308. Acesso em: 26 Fev. 2018.

- Culturas juveniles. Formas políticas del desencanto. Buenos Aires: Siglo Veintiuno Editores, 2012.

ROCHA, E.; PEREIRA, C.; BALTHAZAR, A. C. Tempo Livre é Tempo Útil:

Gadgets, entretenimento e juventu de. Trabalho apresentado ao Grupo de Trabalho "Mídia e Entretenimento", do XIX Encontro da Compós, na PUCRio., Rio de Janeiro, RJ, jun 2010.

ROSA, H. C. Juventude e Mídia: Uso dos aparelhos eletrônicos móveis nas salas de aula. ANAIS do XXVI Simpósio Nacional de História, São Paulo, Jul. 2011. p. 1-8.

SANTOS, B. D. S. A gramática do tempo: para uma nova cultura política. São Paulo: Cortez, 2008.

SCHMIDT, S. Ter Atitude: Juventude Líquida na Pauta - Um estudo sobre mídia e cultura jovem global. XVI COMPÓS UTP. Grupo de Trabalho Recepção, Usos e Consumo Midiáticos, Curitiba, PR, Jun. 2007. 